Research Article

\title{
Crack Group Effect Analysis of the Stress-Release Boot of Solid Rocket Motor Based on Numerical Simulation
}

\author{
Tianpeng Li, ${ }^{1,2}$ Junli Han $\mathbb{D}^{,},{ }^{3}$ Yong He, ${ }^{1}$ and Yu Guo ${ }^{4}$ \\ ${ }^{1}$ Nanjing University of Science and Technology, Nanjing 210094, China \\ ${ }^{2}$ Army Engineering University, Shijiazhuang 050003, China \\ ${ }^{3}$ Beijing Institute of Special Electromechanical Technology, Beijing 100012, China \\ ${ }^{4}$ National University of Defense Technology, Changsha 410073, China
}

Correspondence should be addressed to Junli Han; hanjunli3390@sina.com

Received 12 September 2021; Accepted 8 November 2021; Published 30 November 2021

Academic Editor: Mohammad Tawfik

Copyright (c) 2021 Tianpeng Li et al. This is an open access article distributed under the Creative Commons Attribution License, which permits unrestricted use, distribution, and reproduction in any medium, provided the original work is properly cited.

\begin{abstract}
Due to the complex process of the insulation layer patch in solid rocket motor (SRM), only manual patch could be used. Sometimes weak bonding or debonding in each joint surface was inevitable. This study is aimed at determining the crack group effect of insulation and interfacial debonded crack in the wide-temperature SRM. The crack group appeared in the front area of the ahead stress-release boot and was induced by low temperature, axial overload, or interface bonding failure. Based on the viscoelastic finite element method, singular crack elements and singular interfacial crack elements at the tips of crack group were established to calculate $J$-integral. Varying according to the length and position of cracks, the $J$-integral of crack tips was, respectively, calculated to prejudge their stability and the crack group effect. The results showed that collinear crack group appeared in the front stress-release boot layer, and the crack group had a certain shielding effect on the main crack when the SRM was launched at low temperature. When noncollinear crack group appeared in the front stress-release boot layer, the crack group effect changed with the length of the main crack. The crack group first had a shielding effect on the main crack and then had a strong strengthening effect. The experimental test of the simulated specimen revealed that numerical simulation results matched the experimental test results.
\end{abstract}

\section{Introduction}

The interface is the most common location for fractures. There are numerous interfaces in solid rocket motor grain, such as shell/insulation, insulation/cladding, and cladding/ propellant. Due to the complexity of the insulation patch process for SRM. At present, only the artificial bonding method can be used to stick the insulation layer. Sometimes weak bonding or debonding in each joint surface was inevitable. These interfaces may lead to interface debonding in the process of curing, cooling, storage, and daily use of the motor. In particular, at present, the solid rocket motor requires wide temperature environmental adaptability. The ambient temperature ranges from $-40^{\circ} \mathrm{C}$ to $50^{\circ} \mathrm{C}$, and most motors are cast-on-wall HTPB propellant motors. The thermal expansion coefficient of the propellant is one order of magnitude higher than that of the shell. At low tempera- tures, the shrinkage deformation of propellant grain is large, resulting in serious stress concentration at both ends of the motor. This results in excessive tensile stress on the bonding surface of the grain and causes debonding. The most effective way to alleviate stress concentration at both ends of motor grain is to preset a certain length of debonding crack in the insulation layer, that is, to create an artificial debonding layer and keep it in an excused state, thereby improving the motor's temperature adaptability $[1,2]$. When the motor is ignited and launched, the fuel gas enters the crack cavity of the artificial debonding layer, resulting in serious stress concentration in the front area of the artificial debonding layer crack, which easily generates crack defects. Most of these defects appear in the form of crack groups. If the crack groups expand unsteadily, this may lead to a change in the internal ballistic performance of the motor $[3,4]$. Catastrophic accidents, such as shell fire penetration and motor 


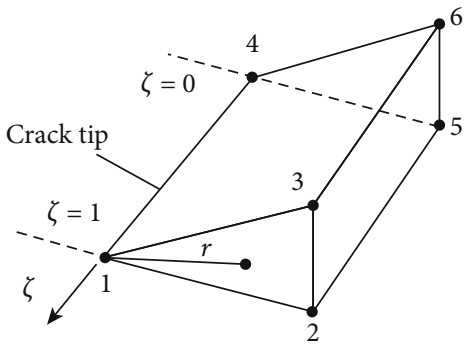

(a) Wedge singular element

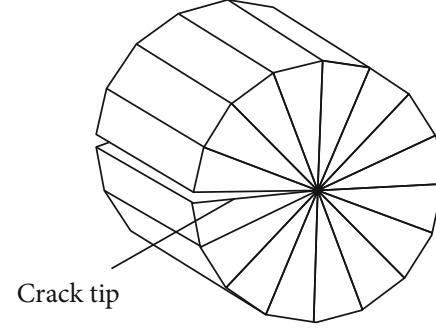

(b) 3D singular crack element

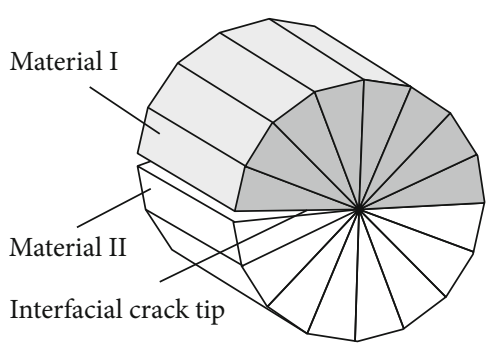

(c) 3D singular interfacial crack element

Figure 1: Building 3D singular crack element and singular interfacial crack element.

explosion, are more serious. Therefore, it is critical to investigate the stability characteristics and group effect of the insulation crack group. Identifying the parameters that control crack propagation in the artificial debonding layer crack group and the interaction effect between physical parameters in the crack group is a critical research topic in the safety research field of solid rocket motor [5].

At present, research on crack groups is primarily focused on the stress intensity factor of elastomers $[6,7]$ and the influence of crack groups on the dynamic characteristics of concrete [8]. However, there is no report on the occurrence of crack groups at the crack tip of artificial debonding layer motor front-end insulation, as demonstrated in this study. Due to the high number of interfaces in the front-end insulation area of this type of motor, some cracks in the crack group are interface cracks. A three-dimensional singular crack element is constructed around each crack tip of the crack group [9]. Under the combined action of low temperature $\left(-40^{\circ} \mathrm{C}\right)$, internal pressure, and axial overload, a singular crack element or interface singular crack element is constructed at each crack tip to calculate $J$-integral of each crack body $[10,11]$. Following that, according to the variation law of $J$-integral of each crack with the number and orientation of cracks, the stability and group effect of artificial debonding layer crack group are discussed.

\section{Construction of Singular Crack Element}

According to fracture mechanics, the crack tip displacement, stress, and $J$-integral are expressed as follows [12]:

$$
\begin{aligned}
& u_{i}=\sqrt{\frac{E}{\pi\left(1-v^{2}\right)} J^{1 / 2} \sqrt{r} f_{1}^{(N)}(\theta),} \\
& \sigma_{i j}=\sqrt{\frac{E}{2 \pi\left(1-v^{2}\right)} \frac{J^{1 / 2}}{r^{1 / 2}} g_{i j}(\theta) .}
\end{aligned}
$$

$r$ is the distance from the crack tip to the point of interest; $E$ is the elastic modulus; $v$ is Poisson's ratio; $\sigma_{i j}(i, j=$ $1,2,3)$ is the stress component; $u_{i j}(i, j=1,2,3)$ is the displacement component; $f_{i}(\theta)$ and $g_{i j}(\theta)$ are polar angle functions.

Typically, researchers use special elements to describe the particularity of the crack tip region $[13,14]$. According to Equations (1) and (2), the first derivative of displacement $u_{i}$ at the crack tip obtains the stress $\sigma_{i j}$, whose first derivative has $r^{-1 / 2}$ singularity. To approximate displacement and stress at the crack tip to the real field, it is necessary to construct a singular element with $r^{-1 / 2}$ displacement behavior so that the stress of the first derivative has $r^{-1 / 2}$ singularity behavior.

As depicted in Figure 1(a), one edge of the eight-node hexahedron element is collapsed to form a six-node wedge singular element, and the shape function is as follows:

$$
\begin{aligned}
& N_{1}(\xi, \eta, \zeta)=N_{1}(\xi, \eta) \zeta, \\
& N_{2}(\xi, \eta, \zeta)=N_{2}(\xi, \eta) \zeta, \\
& N_{3}(\xi, \eta, \zeta)=N_{3}(\xi, \eta) \zeta, \\
& N_{4}(\xi, \eta, \zeta)=N_{4}(\xi, \eta)(1-\zeta), \\
& N_{5}(\xi, \eta, \zeta)=N_{2}(\xi, \eta)(1-\zeta), \\
& N_{6}(\xi, \eta, \zeta)=N_{3}(\xi, \eta)(1-\zeta)
\end{aligned}
$$

The three-dimensional singular crack element comprises 16 and 8 collapsed hexahedron elements, as depicted in Figures 1(b) and 1(c), respectively. The number of singular elements is arbitrary and can be increased or decreased according to the structure's characteristics. A basic singular crack element requires at least eight singular elements. As the number of singular elements increases, its calculation accuracy is improved accordingly.

\section{Solution of $J$-Integrals between Three-Dimensional Cracks and Interfacial Cracks}

The division of three-dimensional interface crack finite elements and the construction method of the J-integral cylinder enclosure are shown in Figure 2. The interface singular crack element is used to describe the interface crack tip whereas other parts without cracks are described by ordinary elements. The solution of the three-dimensional $J$-integral value of each crack and interface crack is mainly divided into two steps [15]: one is to calculate the two-dimensional $J$ integral of the end crack as shown in Figure 2(a) and the plane $\left(x_{1}-x_{2}\right)$ is perpendicular to the line in front of the crack (the intersection is node $O$ ). 


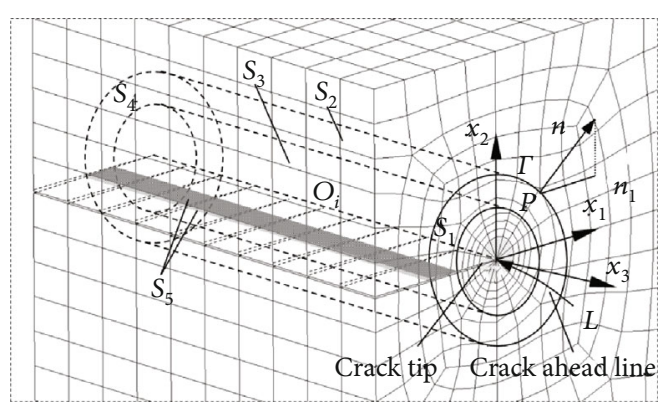

(a) 3D crack element meshing and $J$-integral loop

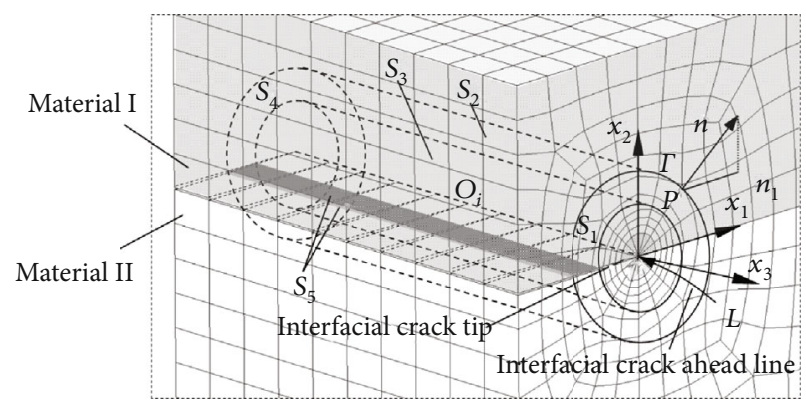

(b) 3D interfacial crack element meshing and $J$-integral loop

FIgURE 2: The crack finite element meshing and 3D J-integral loop surface.

The second step is to integrate the two-dimensional $J$-integral point by point along the front line of the crack to obtain the three-dimensional $J$-integral. In the structural finite element division, a closed cylindrical enclosure is constructed to surround the singular crack elements along the front line of the crack, as shown in Figure 2(a). The $S_{2}$ and $S_{3}$ are the outer surfaces and inner surfaces of the cylindrical enclosure, respectively. On the other hand, $S_{1}$ and $S_{4}$ are divided into two end faces of the cylindrical enclosure surface whereas $S_{5}$ is the two crack surfaces of the cracked body. For the interface crack, integrate the two-dimensional $J$-integral point by point along the front line of the interface crack to obtain the three-dimensional $J$-integral along the front line of the interface crack as shown in Figure 2(b). A closed cylindrical enclosure surface is formed to surround the front line of the interface crack. The two end surfaces of the cylindrical enclosure surface are $S_{1}$ and $S_{4}$, the outer surface $S_{2}$, the inner surface $S_{3}$, and the upper and lower interface crack surface $S_{5}$.

The surfaces $S_{1}, S_{2}, S_{3}, S_{4}$, and $S_{5}$ together form the volume domain $\mathrm{V}$. The surface integral can be transformed into volume integral by Gauss theorem $[4,10]$.

$$
J=-\int_{V} \frac{\partial}{\partial X}\left[\omega(\varepsilon) I-\sigma \frac{\partial}{\partial X} \bar{\rho}\right] d v-\int_{s_{1}+s_{4}+s_{5}} \sigma_{s} \bar{\rho} d s
$$

$\omega$ is the strain energy, and $n$ is the normal direction outside the surface. The unit vector of interface crack propagation direction was $\rho$ whereas $\bar{\rho}$ is the volume weight function, the modulus of $\bar{\rho}$ on the outer surface $S_{2}$ is $0, \bar{\rho}=\delta(l) \rho$ on the inner surface $S_{3}$, and $\bar{\rho}$ changes smoothly between two values in the surface. $\sigma_{s}$ is the surface tension on end faces $S_{1}, S_{4}$, and interface crack surface $S_{5}$. The $J$-integral of each node $O_{i}$ along the line before the interface crack can be expressed as follows:

$$
J_{0 i}=\frac{J}{\int_{L} \delta(l) d l}
$$

$\delta(l)$ is the length of the node $O i$ along the front of the interface crack.

\section{Experimental Measurement and Numerical Calculation of Critical $J$-Integral of Interfacial Debonding Crack}

The insulation layer, cladding layer, and propellant belonged to viscoelastic material. There is no standard for the measurement of crack fracture toughness. The $J$-integral measurement method of metal material in GB2038-91 is adopted [16].

The test pieces were made containing annular cracks in the insulation layer, cladding layer, and propellant, as well as shell/insulation layer interface crack, insulation layer/ cladding layer interface crack, and cladding layer/propellant interface crack. Figure 3 is the design diagram of the insulation layer/cladding layer interface crack test piece, and Figure 4 is the diagram of the sample before and after the simulation test piece experiment and the tensile test device. The interface debonding of insulation/cladding was cut into annular debonding cracks with depth $a$, outer diameter $d$, and inner diameter $d-2 a$. The interface $J$-integral is obtained $[17,18]$ from the following solution formula:

$$
J=\frac{\varepsilon W}{\left.\pi(d-2 a / 2)^{2}\right|_{u}} .
$$

$\varepsilon$ is the geometric influence factor, and $W$ is the integral of load-displacement curve.

The value of $\varepsilon$ is calibrated by the multisample method. According to the theory of fracture mechanics, the $J$-integral under fixed boundary displacement $u$ is as follows [19]:

$$
J=\frac{-d W}{\left.d S\right|_{u}} .
$$

$S$ is the initial fracture ligament area of the cracked body, $S=\pi a(d-a)$. Factor $\varepsilon$ is obtained by comparing formulas (6) and (7) as follows:

$$
\eta=-\frac{(d-2 a)}{4 W} \frac{d W}{d a} .
$$

$\varepsilon$ is calibrated by multisample method, and the critical $J$ integral $J_{\text {IC }}$ of propellant at different tensile rates is determined by single sample method and Equation (6). $J_{\text {IC }}$ is 


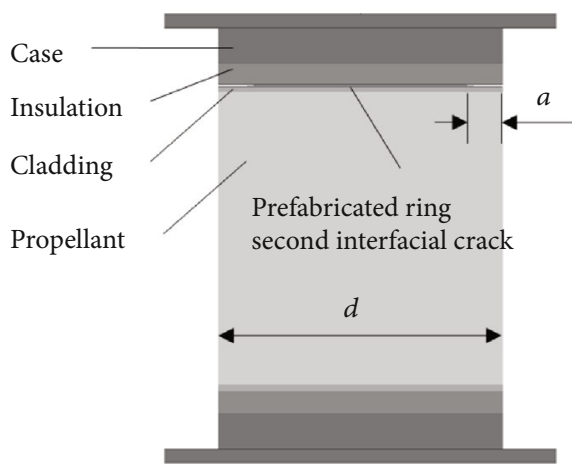

Figure 3: The design of insulation/cladding interface debonded crack specimen.

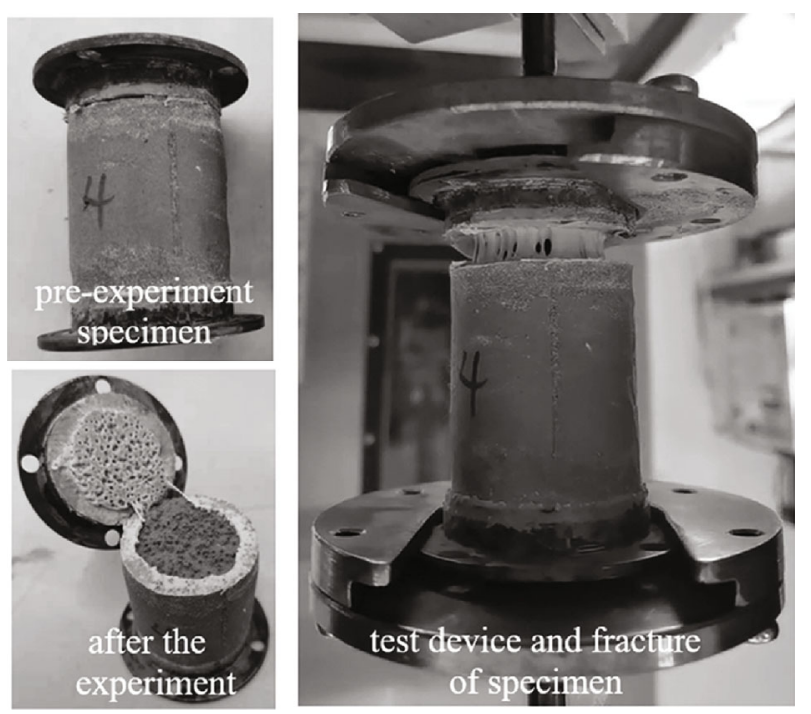

Figure 4: The insulation/cladding interface debonded crack specimen and tensile test device.

related to tensile rate and temperature. The $J_{\text {IC }}$ of propellant at the tensile speed of $20 \mathrm{~mm} / \mathrm{min}$ was measured at room temperature, and five experimental samples with different debonding crack depths were prepared. The forcedisplacement curve was obtained through the uniaxial tensile test, and the input energy $W$ was calculated by integration. $W-a$ curves of five specimens with different crack lengths were obtained, and $d W / d a$ was fitted. The value of $a$ is obtained from Equation (8), and $J_{\mathrm{IC}}$ is obtained from Equation (6). The experimental results reveal that $J_{\text {IC }}$ of the annular crack in the insulation layer is $1.419 \pm$ $0.050 \mathrm{Nmm} / \mathrm{mm}^{2}$, the $J_{\mathrm{IC}}$ of the crack in the cladding layer is $0.618 \pm 0.050 \mathrm{Nmm} / \mathrm{mm}^{2}$, the $J_{\text {IC }}$ of the propellant grain is $0.767 \pm 0.050 \mathrm{Nmm} / \mathrm{mm}^{2}$, the $J_{\mathrm{IC}}$ of the I interface crack is $1.737 \pm 0.050 \mathrm{Nmm} / \mathrm{mm}^{2}$, the $J_{\text {IC }}$ of the II interface crack is $1.216 \pm 0.050 \mathrm{Nmm} / \mathrm{mm}^{2}$, and the $J_{\text {IC }}$ of the III interface crack is $0.687 \pm 0.050 \mathrm{Nmm} / \mathrm{mm}^{2}$.

Figure 5 is the three-dimensional finite element calculation model of thermal insulation/cladding interface debonding simulation test piece, and the three-dimensional singular crack element is constructed at the crack tip. Figure 5 is the finite element local model when the circumferential debonding crack with a depth of $5.0 \mathrm{~mm}$. The front line of debonding crack is composed of 84 circumferential nodes. The radius of $J$-integral along the crack front was set, the critical $J$-integral value of debonding crack specimen was calculated at the interface of insulation/cladding at room temperature, and the $J$-integral of each crack and interface debonding crack front in Figure 6 corresponds to the value of each node.

The crack initiation time of the specimen with a debonding crack at the interface of insulation/cladding under loading is determined by image records in the experimental process. The critical tensile displacement and load when a crack occurs are determined by comparing the displacement time curve in the testing machine, providing a reliable basis for determining the boundary conditions by numerical calculation. The relative error between the calculated average $J_{\text {IC }}$ of the crack tip and the measured value is less than $4.5 \%$. The results reveal that the fracture finite element method exhibits high accuracy in analyzing the critical $J_{\text {IC }}$ of cracks and interfacial debonding cracks.

\section{Construction of Solid Rocket Motor Propellant Finite Element Model}

Figure 7 is a three-dimensional finite element model and schematic diagram of constituent materials of a solid rocket motor. The motor charge type is a star hole charge type structure. According to the axial symmetry of motor bearing temperature, internal pressure, and axial overload, the model can be modeled using cyclic symmetry characteristics of motor structure. This motor type has ten cyclic symmetrical parts, one of which is taken to build the model. The finite element scale is divided into 151656 hexahedral elements and 176690 nodes.

The motor grain mainly includes a shell/insulation layer, insulation/cladding layer, and cladding layer/propellant interface. The interface singular crack element is used to simulate the mechanical behavior of the interface crack tip and the debonding and propagation of the interface crack along the bonding surface. Under the action of temperature, internal pressure, and axial overload, the variation trend of $J$-integral value of each node along the front line of interface crack with interface debonding depth is calculated. If the $J$-integral of interface crack reaches or exceeds the critical $J$-integral $J_{\text {IC }}$ of the interface crack, the interface crack will debond and crack along the bonding surface.

The load condition of low-temperature ignition and emission is that the pressurization time is $60 \mathrm{~ms}$, the peak pressure is $16.5 \mathrm{MPa}$, the axial overload is $25 \mathrm{~g}$, and the temperature is $-40^{\circ} \mathrm{C}$. The mechanical property parameters of each component material of the motor are shell elastic modulus $2.05 \times 10^{5} \mathrm{MPa}$ and Poisson's ratio 0.28 , and Poisson of propellant is 0.496 . The relaxation modulus of low-temperature insulation, cladding, and propellant are measured, and Prony series is proposed (take $N$ items) $[20,21]$ :

$$
E(t)=E_{\infty}+\sum_{n=1}^{N} E_{n} e^{-t / \tau_{n}}
$$




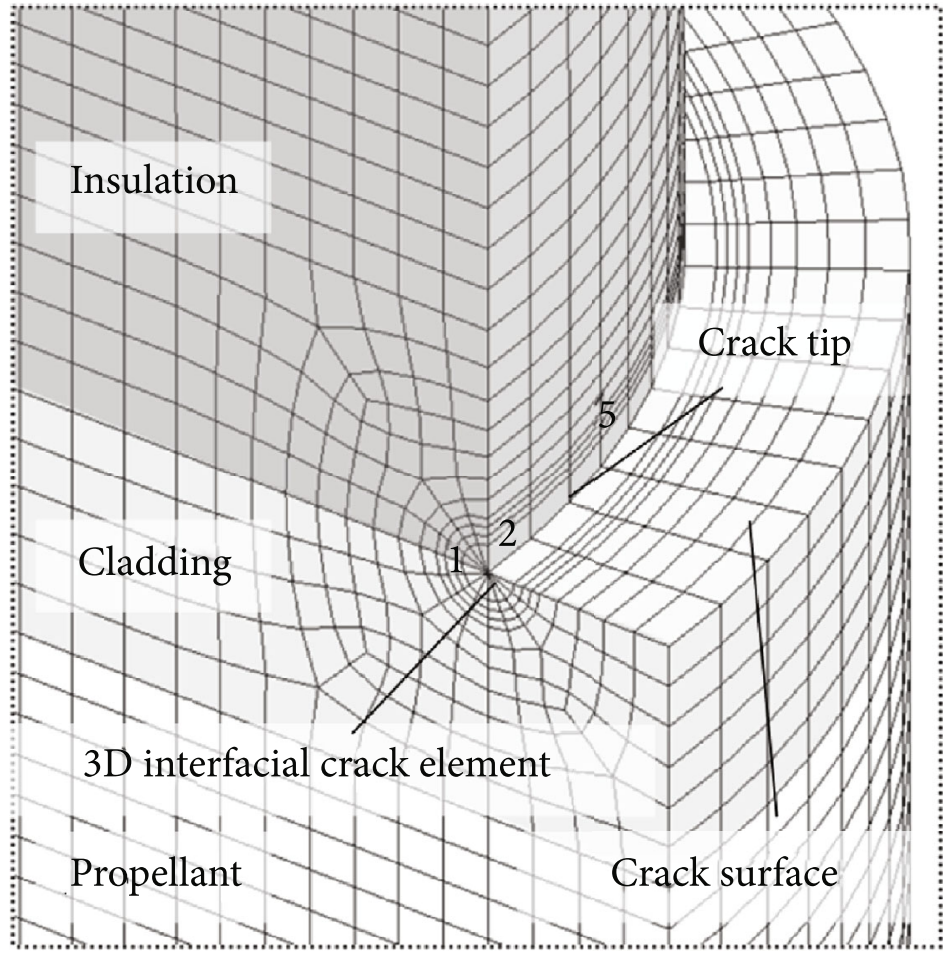

FIgURE 5: The interface debonded specimen model and 3D interfacial crack element meshing.

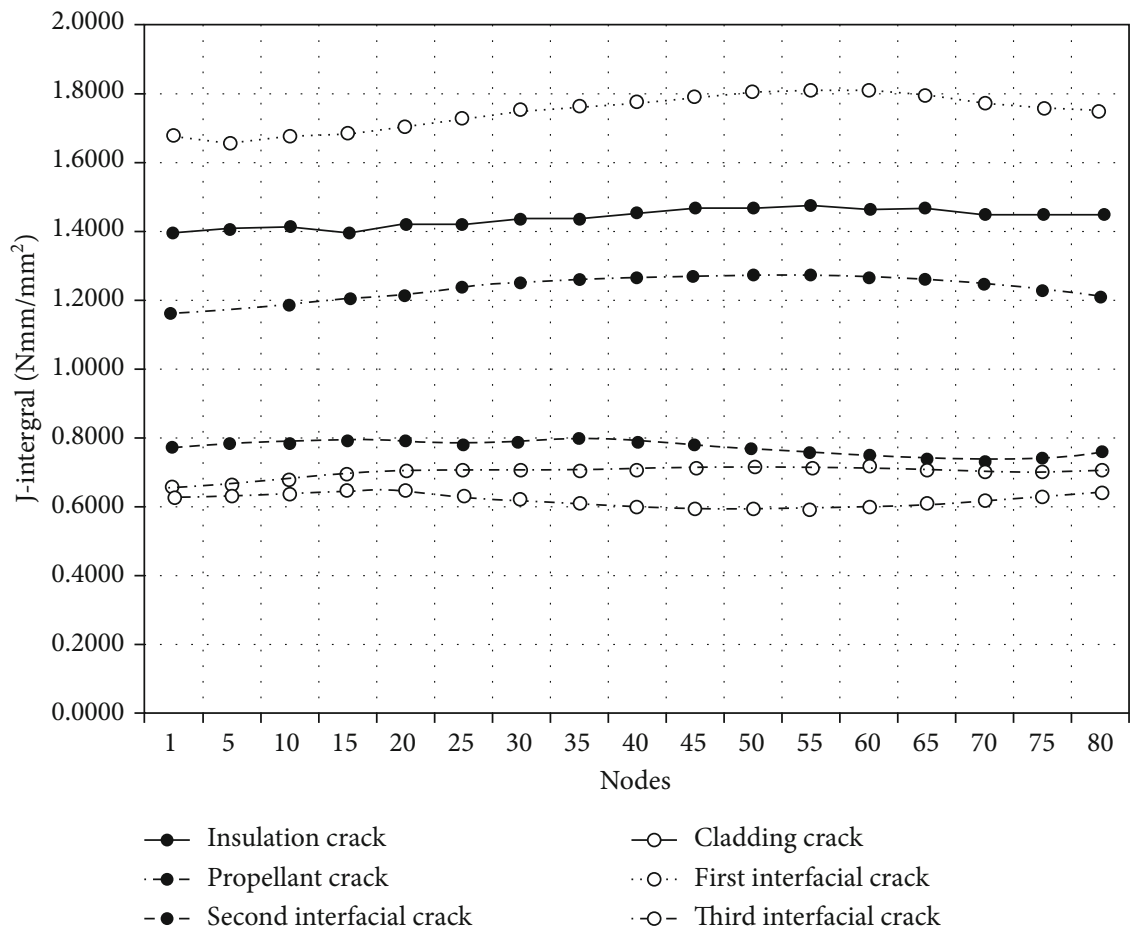

FIgURE 6: The $J$-integral of cracks and interfacial crack initiation. 


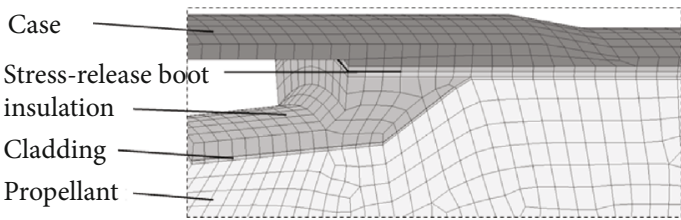

(a) Composing materials.

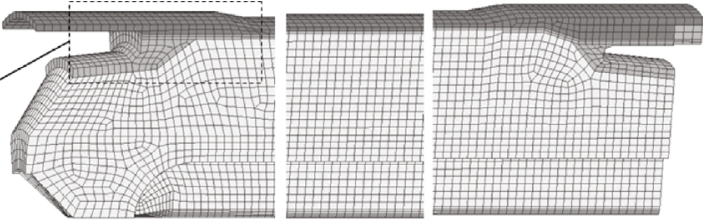

(b) $1 / 10$ finite element model.

FIGURE 7: Composing materials and 3D finite element model of SRM grain.

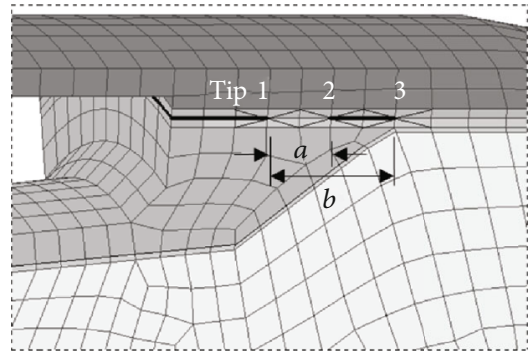

(a) Double collinear cracks

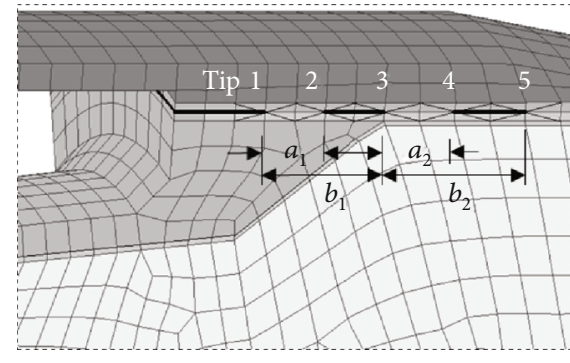

(b) Three collinear cracks

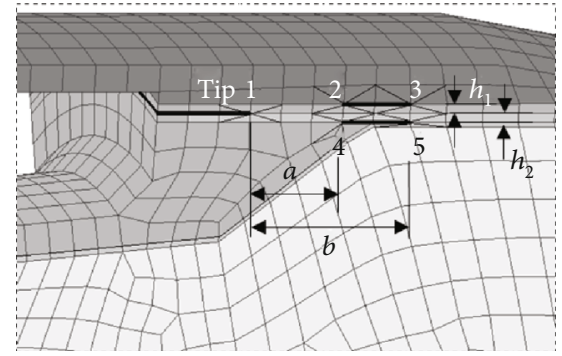

(c) Three noncollinear cracks

FIGURE 8: The insulation crack group in the fore area of stress-release boot of SRM grain.

where $E_{\infty}$ is the permanent relaxation modulus $(t \longrightarrow \infty), E_{n}$ is the elastic modulus (the $n^{\text {th }}$ Maxwell unit), and $\tau_{n}$ is the relaxation time.

\section{Analysis of Crack Group Effect of Artificial Debonding Layer}

As depicted in Figure 8, under low-temperature ignition and launch conditions, the von Mises strain concentration of the artificial debonding layer in front of the solid rocket motor is serious. The crack group effect in the insulation layer is investigated in the stress concentration region using one or two collinear axial cracks and three cracks along the crack extension line at the crack end of the artificial debonding layer (tip 1, located in the insulation layer). Simultaneously, a basic three-dimensional singular crack element is set around the tip of each crack front of the crack group to obtain a relationship between $J$-integral of each crack tip of the insulation layer and position parameters $a, b$, and $h_{i}$. Especially for noncollinear three cracks, engineering experience shows that the interface is often a key part of debonding cracks. In the noncollinear interface crack group, except for the artificial debonding layer, crack is located in the insulation layer; other cracks are located on each interface. In this model, the interface crack length is $b-a$, the tip distance is $a$ , and the interface crack parallel spacing is $h_{i}$. A threedimensional interface singular crack element is set around the front tip of each interface crack of the crack group, and the relationship between the $J$-integral of each interface crack tip and the position parameters $a, b$, and $h_{i}$ can be obtained.

The $J$-integral criterion is used to explore the crack group effect. The test results indicate that the $J_{\text {IC }}$ of propellant grain is $0.767 \mathrm{Nmm} / \mathrm{mm}^{2}$, the $J_{\text {IC }}$ of crack in insulation layer is $1.419 \mathrm{Nmm} / \mathrm{mm}^{2}$, the $J_{\mathrm{IC}}$ of crack in cladding layer is
$0.618 \mathrm{Nmm} / \mathrm{mm}^{2}$, the $J_{\text {IC }}$ of crack at shell/insulation layer interface (interface I) is $1.737 \mathrm{Nmm} / \mathrm{mm}^{2}$, and the $J_{\text {IC }}$ of crack at insulation layer/cladding layer interface (interface II) is $1.216 \mathrm{Nmm} / \mathrm{mm}^{2}$. The $J_{\text {IC }}$ of cladding/propellant interface (III interface) crack is $0.6872 \mathrm{Nmm} / \mathrm{mm}^{2}$.

Figure 9 illustrates the collinear double crack distribution of artificial debonding layer crack of the insulation layer, and it is found that the secondary crack length affects the $J$-integral of artificial debonding layer crack. Figure 10 depicts the collinear three crack distribution of artificial debonding layer crack in the insulation layer. It is found that the third crack length affects the $J$-integral of artificial debonding layer crack. Figure 11 shows that the artificial debonding layer crack is located at the insulation layer, and the two noncollinear interface cracks are located at the shell/insulation layer and the insulation/cladding layer interface, respectively. It is found that the change of distance between the artificial debonding layer crack and the two interface cracks affects the $J$-integral of artificial debonding layer crack.

The calculation results reveal that when there is a single crack (artificial debonding layer crack) in the insulation layer, the $J$-integral of the crack tip (tip 1) is $0.9613 \mathrm{Nmm} /$ $\mathrm{mm}^{2}$, which is less than the critical integral $J_{\text {IC }}$ of insulation layer, and the safety factor is 1.48 . The artificial debonding layer crack in the insulation layer is stable. Figure 9 shows that in the front area of artificial debonding layer crack, with the appearance of collinear secondary cracks, the $J$-integral of artificial debonding layer crack of the insulation layer decreases. Therefore, the collinear crack has a shielding effect on the artificial debonding layer crack, the weakening range is about $26.8 \%$, and the artificial debonding layer crack is a safe crack. As the secondary crack length increases, the $J$-integral between the artificial debonding layer crack and both ends of the secondary crack tip shows a downward 


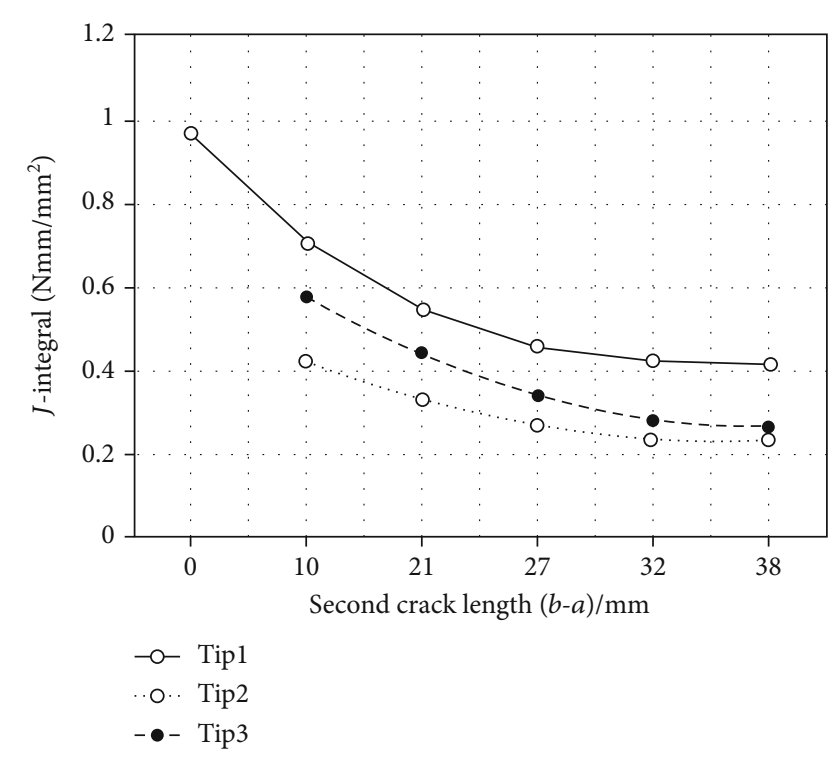

Figure 9: The $J$-integral variation with the second crack of double collinear insulation cracks.

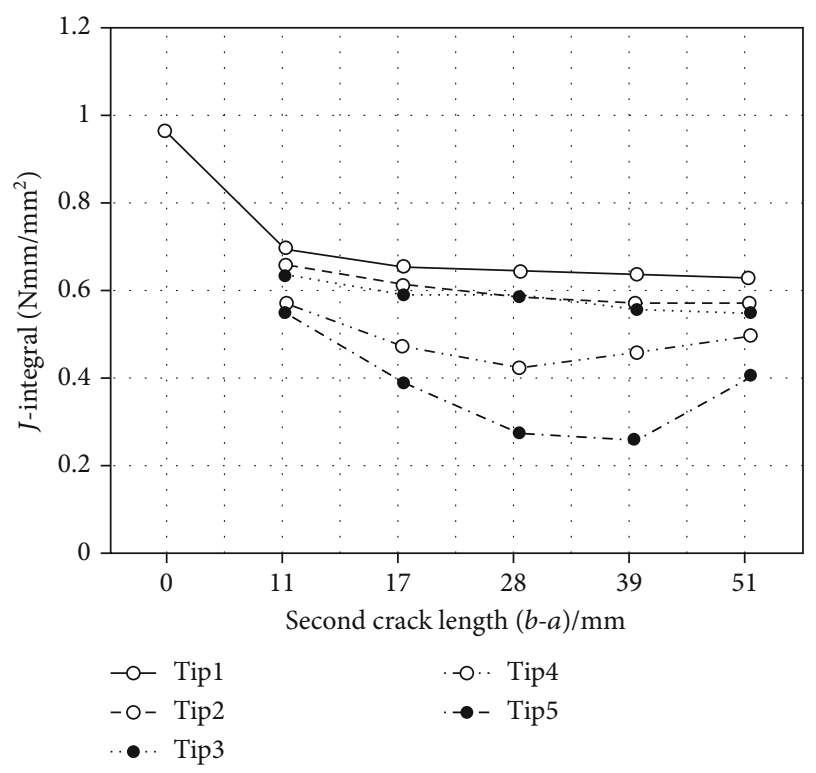

Figure 10: The $J$-integral variation with the third crack of three collinear insulation cracks.

trend. When the secondary crack length reaches $27 \mathrm{~mm}$, the downward trend is slow, indicating that the influence of increasing secondary crack length on the artificial debonding layer crack is weakening. As Figure 10 displays, in the front area of artificial debonding layer of the insulation layer, when the length of the secondary crack in the collinear crack group is $11 \mathrm{~mm}$, there are collinear three crack groups. The decrease of $J$-integral of artificial debonding layer crack is slightly larger than that of the double crack, with a decreased range of $27.7 \%$. All cracks in the insulation layer are safety cracks. The change of the third crack length in the insulation layer has little effect on the $J$-integral at the crack tip of artificial debonding layer crack and the secondary crack in the insulation layer. As the third crack length increases, the $J$-integral at the crack tip of artificial debonding layer crack, the secondary crack decreases slowly. Within the third crack length of $51 \mathrm{~mm}$, the weakening amplitude is no more than $2 \%$, and each crack in the insulation layer is stable.

As illustrated in Figure 11, once the noncollinear interface crack group appears, the artificial debonding layer crack and each insulation layer interface crack are safe cracks. The distance $(a)$ between the artificial debonding layer crack and the noncollinear interface crack decreases until it reaches $5 \mathrm{~mm}$ between the shell/insulation layer and the insulation/ cladding layer interface crack $(a<0)$, the $J$-integral of artificial debonding layer crack, the secondary crack, and the third crack near the end crack tip (tip 2 and tip 4, respectively) decreases sharply. When the distance $(a)$ is 15,10 , 5 , and $0 \mathrm{~mm}$, the $J$-integral of artificial debonding layer crack decreases by $27.7 \%, 36.8 \%, 42.3 \%$, and $56.3 \%$, respectively, and especially when $(a)$ is $-5 \mathrm{~mm}$, it decreases by $75.3 \%$, indicating very obvious shielding phenomenon. The $J$-integral of distal interface crack tip (tip 3 and tip 5, respectively) increases slightly with the approach to the artificial debonding layer crack, with an enhancement amplitude of no more than $3 \%$. When $(a)$ is $-7.5 \mathrm{~mm}$, the $J$-integral of main crack in the artificial debonding layer increases sharply. When $(a)$ is about $-11 \mathrm{~mm}$, the J-integral of main crack reaches the critical $J$-integral of insulation layer. As the main crack grows, the $J$-integral of main crack exceeds the critical $J$-integral of insulation layer, corresponding to the maximum point of $J$-integral $(a=-12.5 \mathrm{~mm})$, which is $69.7 \%$ higher than the original $J$-integral value. At this time, the main crack expands unsteadily. When $(a)$ is $-11 \mathrm{~mm}$ $15 \mathrm{~mm}$, the enhancement effect of crack group is very obvious. The $J$-integral of original proximal interface crack tip (tip 2 and tip 4, respectively) increases with the crack propagation of artificial debonding layer, whereas the $J$-integral of original distal interface crack tip (tip 3 and tip 5, respectively) mainly decreases.

The results indicate that once the crack group appears at a certain distance from the front end of motor's artificial debonding layer crack, the crack group weakens the $J$-integral of artificial debonding layer crack under the condition of low-temperature ignition and emission, and the number of crack groups in the collinear crack group is directly proportional to the weakening amplitude. Each crack and interface crack in the insulation layer crack group are safe cracks. The length change of thermal insulation crack group has different degrees of shielding effect on the $J$-integral of artificial debonding layer crack. The collinear crack group has the greatest influence on the secondary crack closest to the artificial debonding layer crack, and the influence weakens with increasing distance. The distance between the artificial debonding layer crack and the interface crack group in the insulation layer is directly proportional to the weakening amplitude. When the crack tip of artificial debonding layer enters the interface crack group area, $(a)$ is $15 \mathrm{~mm} \sim-5 \mathrm{~mm}$, and the shielding effect is very obvious, and when $(a)$ is $-5 \mathrm{~mm} \sim-15 \mathrm{~mm}$, the enhancement effect of the crack group is very obvious. 


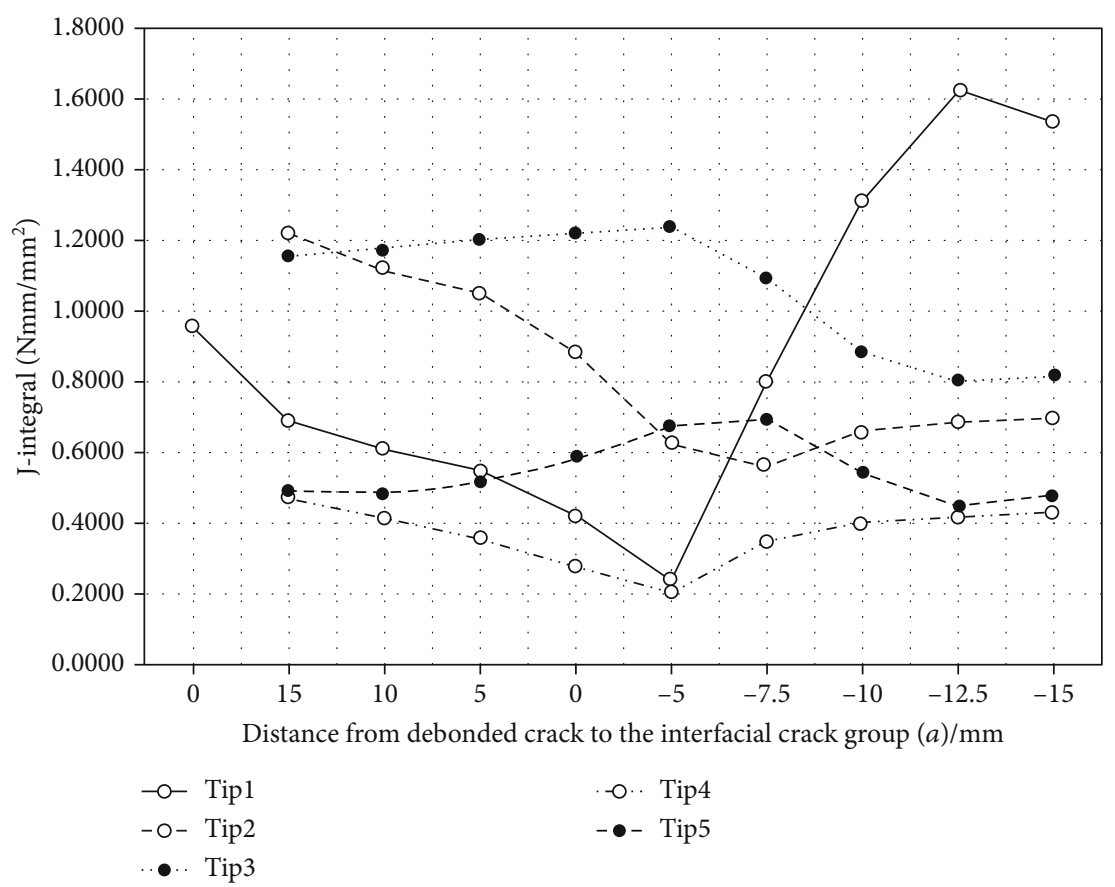

FIGURE 11: The $J$-integral variation with the distance of three noncollinear interfacial cracks.

\section{Conclusion}

By constructing a three-dimensional singular element and grain finite element model of the artificial debonding layer crack of a solid rocket motor, the crack groups such as collinear double crack, collinear three crack, and noncollinear interface crack are set in the front area of artificial debonding layer crack. The $J$-integral of each crack tip of the crack group during low-temperature ignition and launch is simulated and calculated according to the J-integral and the spatial position of the crack group. The crack group effect of artificial debonding layer is discussed. The main conclusions are as follows:

(1) Under normal conditions, the crack in the manual debonding layer of grain is a stable crack, and the debonding crack does not expand during ignition

(2) In the case of collinear double cracks, secondary cracks appear at a certain distance (less than $20 \mathrm{~mm}$ ) in front of the crack tip of artificial debonding layer, causing a shielding effect. As the secondary crack length increases, the $J$-integral shielding effect on the artificial debonding layer crack increases slowly

(3) In the case of collinear three cracks, the influence of the secondary crack group on the J-integral at the crack tip of artificial debonding layer is inversely proportional to the distance. The change of length of the third crack has a negligible influence on the crack of artificial debonding layer. As the length of the third crack increases to $51 \mathrm{~mm}$, the shielding effect does not exceed 2\%. The shielding effect of the third crack on the crack of artificial debonding layer is not obvious

(4) In the case of noncollinear interface cracks, the influence of the noncollinear interface crack group on the $J$-integral at the crack tip of artificial debonding layer is directly proportional to the distance. From $20 \mathrm{~mm}$ to the interface crack group, the shielding effect becomes significant. When the distance is $-5 \mathrm{~mm}$, the shielding rate is as high as $75.3 \%$. At this time, the whole artificial debonding layer crack group has improved in terms of safety and stability. When the distance is $-12.5 \mathrm{~mm}$, the enhancement rate is as high as $69.7 \%$, and the crack of artificial debonding layer expands unsteadily

\section{Data Availability}

The data used to support the findings of this study are available from the corresponding author upon request (hanjunli3390@sina.com).

\section{Conflicts of Interest}

The authors declare no conflict of interest.

\section{Authors' Contributions}

Writing-original draft preparation was contributed by Tianpeng Li; conceptualization and methodology were contributed by Junli Han; resources and writing-review and editing were contributed by Yong He; software was contributed by Yu Guo. All authors have read and agreed to the published version of the manuscript. 


\section{Acknowledgments}

This work was supported by the National Natural Science Foundation of China (No. 51606098).

\section{References}

[1] S. Y. Meng, G. Y. Hu, B. Liu, and W. Peng, "Analysis of stability of crack in solid rocket motor grain with J-integral," Journal of Solid Rocket Technology(JSRT), vol. 33, no. 6, pp. 646-649, 2010.

[2] R. López, A. Ortega de la Rosa, A. Salazar, and J. Rodríguez, "Structural integrity of aged hydroxyl-terminated polybutadiene solid rocket propellant," Journal of Propulsion and Power, vol. 34, no. 1, pp. 75-84, 2018.

[3] G. Zhou, X. Yin, and A. Li, "Study on the fracture toughness of hydroxyl-terminated polybutadiene solid rocket propellant," Journal of Propulsion and Power, vol. 31, no. 3, pp. 912-918, 2015.

[4] J. T. Li, Y. J. Lei, G. J. Tang, S. Y. Meng, and D. C. Yuan, “Analysis on surface crack of solid rocket motor grain," Journal of Solid Rocket Technology, vol. 5, 2008.

[5] M. A. Willcox, M. Q. Brewster, K. C. Tang, D. S. Stewart, and I. Kuznetsov, "Solid rocket motor internal ballistics simulation using three-dimensional grain burnback," Journal of Propulsion and Power, vol. 23, no. 3, pp. 575-584, 2007.

[6] V. N. Shlyannikov and A. P. Zakharov, "Generalization of mixed mode crack behaviour by the plastic stress intensity factor," Theoretical and Applied Fracture Mechanics, vol. 91, pp. 52-65, 2017.

[7] M. Ayatollahi and M. Nourazar, "Multiple mixed-mode cracks in a magneto-electro-elastic half-plane under in-plane loading," Engineering Fracture Mechanics, vol. 232, article 107009, 2020.

[8] S. Rajasekaran and H. B. Khaniki, "Free vibration analysis of bi-directional functionally graded single/multi-cracked beams," International Journal of Mechanical Sciences, vol. 144, pp. 341-356, 2018.

[9] R. Daimon and H. Okada, "Mixed-mode stress intensity factor evaluation by interaction integral method for quadratic tetrahedral finite element with correction terms," Engineering Fracture Mechanics, vol. 115, pp. 22-42, 2014.

[10] S. E. Mousavi and N. Sukumar, "Generalized Gaussian quadrature rules for discontinuities and crack singularities in the extended finite element method," Computer Methods in Applied Mechanics and Engineering, vol. 199, no. 49-52, pp. 3237-3249, 2010.

[11] Z. A. Jassim, N. N. Ali, F. Mustapha, and N. A. Jalil, "A review on the vibration analysis for a damage occurrence of a cantilever beam," Engineering Failure Analysis, vol. 31, pp. 442-461, 2013.

[12] T. L. Anderson, Fracture Mechanics: Fundamentals and Applications, CRC press, 2017.

[13] T. J. Hughes and J. E. Akin, "Techniques for developing 'special'finite element shape functions with particular reference to singularities," International Journal for Numerical Methods in Engineering, vol. 15, no. 5, pp. 733-751, 1980.

[14] J. Bulling, H. Gravenkamp, and C. Birk, "A high-order finite element technique with automatic treatment of stress singularities by semi-analytical enrichment," Computer Methods in Applied Mechanics and Engineering, vol. 355, pp. 135-156, 2019.
[15] S. Y. Meng, J. L. Han, C. S. Liu, and X. H. Yang, "Stability analysis of cracks in the stress-release boot of solid rocket motor grain with J-integral," in advanced materials research, vol. 328, pp. 1210-1215, Trans tech publications ltd., 2011.

[16] B. Sun, Y. X. Duo, and S. Y. Meng, "Stability analysis of the interfacial debonded crack in solid rocket motor grain with the J integral," Transactions of Beijing institute of Technology, vol. 38, no. 2, pp. 124-129, 2018.

[17] B. Han, Y. Ju, and C. Zhou, "Simulation of crack propagation in HTPB propellant using cohesive zone model," Engineering Failure Analysis, vol. 26, pp. 304-317, 2012.

[18] Q. C. Zhou, Y. T. Ju, Z. Wei, B. Han, and C. S. Zhou, "Cohesive zone modeling of propellant and insulation interface debonding," The Journal of Adhesion, vol. 90, no. 3, pp. 230-251, 2014.

[19] H. El Bhilat, A. Hachim, H. Salmi, and K. El Had, "Experimental and numerical investigation of the influence of temperature on the fracture behavior of high impact polystyrene evaluated by the J-integral approach using multiple specimen method," Journal of Metals, Materials and Minerals, vol. 30, no. 3, 2020.

[20] X. Tong, X. Chen, J. S. Xu, Y. Zheng, and S. J. Zhi, “The heat build-up of a polymer matrix composite under cyclic loading: experimental assessment and numerical simulation," International Journal of Fatigue, vol. 116, pp. 323-333, 2018.

[21] H. R. Cui, G. J. Tang, and Z. B. Shen, "Study on the viscoelastic poisson's ratio of solid propellants using digital image correlation method," Propellants, Explosives, Pyrotechnics, vol. 41, no. 5, pp. 835-843, 2016. 